\title{
Performance studies on cryogenic treated carbide cutting tool for turning of AISI304 steel
}

\author{
Nagraj Patil ${ }^{1,2 *}$, Gopalakrishna K ${ }^{3}$, Sangmesh B ${ }^{3}$, K Sudhakar ${ }^{4}$, G C Vijaykumar $^{3}$ \\ ${ }^{1}$ Department of Mechanical Engineering, School of Engineering and Technology, \\ Jain University, Bangalore 562112, Karnataka, India \\ ${ }^{2}$ Research scholar,Visvesvaraya Technology University, Belagavi 590018, Karnataka, India \\ *Email: nagrajpatil81@gmail.com \\ Mobile: +91 9590785153; Fax: +9180-27577199 \\ ${ }^{3}$ Centre for Incubation, Innovation, Research and Consultancy (CIIRC), \\ Jyothy Institute of Technology, Bangalore 560082, Karnataka, India \\ ${ }^{4}$ Faculty of Mechanical Engineering, Universiti Malaysia Pahang 26600 Pahang, Malaysia
}

\begin{abstract}
This paper attempts to compare and contrast cryogenic treated and untreated carbide cutting tool in turning operation of AISI304 steel. Machining parameters, namely cutting speed, feed rate and depth of cut are optimized for cryogenic treated tools. Tool life of the insert was determined based on the tests performed such as hardness, surface roughness and maximum wear. A design of experiments (DOE) and an analysis of variance (ANOVA) have been incorporated in the study. The objective of the paper is to determine the effects of each parameter on the surface roughness and tool wear. Material characterization was carried out using scanning electron microscope (SEM) and the maximum wear was estimated using optical microscope before and after the cryogenic treatment. The experimental results showed that cryogenic treated cutting tools significantly reduction in surface roughness, improves resistance to wear than untreated one. A confirmation test was performed between experimental and optimum values and the results are found to be in good agreement.
\end{abstract}

Keywords: Cryogenic treatment; tool wear; surface roughness; Taguchi method; ANOVA.

\section{INTRODUCTION}

The main challenge in machining is to achieve high accuracy in terms of dimensional accuracy of surface roughness and less tool wear. The lower thermal conductivity, high strength, high ductility made Austenitic AISI304 stainless steels harder material, which lead to difficulty in machining. A high impact surface and tool wear were normally experienced during machining of AISI304 materials because of their high strength and high ductility. However, a superior surface is the most essential parameter to decide the nature of the product and is precision to enhance, wear protection, and weariness quality, of fabricated items. Deep cryogenic treatment is normally preferred in the machining to improve their microstructure properties of the material, which convert retained austenite to martensite as the martensite is the hardest phase in the iron carbon diagram. The presence of martensite phase in the material improves the hardness property. The deep cryogenic treatment involves a low-temperature treatment process around $-176^{\circ} \mathrm{C}$ using liquid nitrogen; it enhances the wear resistance, surface roughness of the cutting tool. Selection of the optimum cutting parameters by using various optimization techniques can avoid to improper selection of the cutting parameters. This causes high manufacturing cost and poor quality of the machined part. 
Hence it is essential to use a systematic tool for optimization of cutting parameters. Taguchi L9 method is the most effective tool used for optimization.

Literatures also reported that few mechanical and physical properties of the cutting tool material can be improved after cryogenic treatment. Sreerama Reddy et al. [1] analyzed the effect of low-temperature treatment on carbide tool insert and untreated insert on the C-45 work piece. It was observed that the flank wear and surface roughness were found to be better in low-temperature treatment carbide insert. Whereas Khan et al. [2] performed an investigation on commercially available titanium grade 2 with cryogenically treated carbide tool insert and untreated tool in a dry cutting environment. The author analyzed the experimental results using Taguchi method L9 orthogonal array and it was found that cryogenically treated insert resist more wear compared to the untreated. Also studied by Akhbarizadeh et al. [3] carried out an experiment for different cryogenic treatment methods such as shallow and deep cryogenic treatment. The results revealed that the deep cryogenic method was performed better in comparison with shallow cryogenic treatment. An increase in percentage of carbide and their homogenous distribution due to cryogenic treatment was studied by Amini et al. [4]. The result indicated an improvement in the hardness and tool wear for optimum holding time. Likewise, Bordin et al. [5] was performed experimentation on applied cryogenic treatment for tungsten carbide insert. It was observed that cryogenic cooling reduces the adhesive wear in comparison with dry machining. Likewise, Das et al. [6] investigated the performance of deep cryogenic treatment and compared their results with conventional heat treatment on AISID2 steel. In another work the use of cryogenic treatment for cutting tool significantly improves tool wear by Dhananchezian et al. [7] studied the effect of liquid nitrogen on rake face turning of Ti-6Al-4V alloy. The result showed that the cryogenic cooling reduces the cutting temperature by $61-66 \%$ surface roughness by $36 \%$ and flank wear by $33 \%$. In this regard Ozbek et al. [8] studied the improvement in coated cryogenic treatment insert in comparison with the uncoated insert in turning of AISI 304 steel. It was found that cryogenically treated insert exhibits superior in wear resistant compare to the uncoated. Similarly, Ozbek et al. [9] performed a test on different soaking time of cryo-treatment for tool wear in turning austenite stainless steel. The study revealed a positive wear resistant for $24 \mathrm{hrs}$ soaking time. It was also observed that increase in hardness and improved microstructure in carbide insert. Yong et al. [10] studied on the cryogenic treatment of tungsten carbide. It was found that cryogenic treatment tool performs better in intermittent machining than continuous. In another work, Seah et al [11] investigated on different condition of treatment of carbide insets. The authors found, improved tool life and wear resistance for cryogenic treatment insert even at higher cutting speed. It was also observed that over all resistance to chipping. Recently, Cryogenic treatment performance was reported by Vadivel et al. [12] investigated on coated cryogenic treated and untreated insert. This result showed coated carbide insert significantly exhibited better results in comparison with untreated insert.

Apart from cryogenic some of the researchers studied on optimization of cutting parameter by using Taguchi technique in this regard, Mahdavinejad et al. [13] adopted a design of experiment for finding the optimum value of tool wear and surface roughness of turning AISI304 stainless steel, using Analysis of Variance. In the study it was analyzed that the most affecting parameter for tool wear is the cutting speed and for surface roughness is the feed rate. In another work Taguchi method of the L9 orthogonal array was studied by Whereas Sitk1 Akıncioglu et al [14] used to optimize the cryogenic treated tool insert in turn of Haste alloy on surface roughness. The results demonstrated that the feed rate contribution was $87.64 \%$ and the results revealed that shallow cryogenic treatment and deep cryogenic process improved the tool wear resistance. Applied Taguchi method by Zerti1 et al. [15] found the effect of cutting parameters under optimum cutting condition in their study. Analysis of variance was used to evaluate the affecting parameter. The study concluded that feed rate was most significant parameter for surface roughness. In another study by E. Daniel Kirby et al. [16] on Taguchi method, it was found that an enhanced tool life and increase in resistance to tool wear was obtained for cryogenic treatment. Likewise, performed an optimization technique on machining parameters by Hascalık et al. [17] using a taguchi orthogonal 
array method. The results revealed that feed rate and cutting speed are the most predominant factor for surface roughness and at tool life. In an experiment conducted by Ramazan Cakırog lu et al. [18] it was found that feed rate is the main affecting parameter for surface roughness and speed was found to be the most affecting parameter for tool wear. In their study, experimental results were found to be in line with design of experiment.

Many researchers have conducted experiment on cryogenic treatment process to improve the properties of carbide insert in this regard, Thakur et al. [19] performed experiment on cryogenic treatment for tungsten carbide inserts subjected to different post treatments. The experimental results indicated a remarkable change in all post-treatment analysis. Similarly, Gill et al. [20] reported that low temperature treated tungsten carbide insert performance was found be good in wet turning condition under different machining conditions and exhibited increase in the tool life in interrupted machining. Similarly, investigated on machining AISI304 stainless steel by Kaladhar et al. [21] on popularly used grade due to their low heat conductivity and high built-up edge formation. The author employed Taguchi methods with a two-layer chemical vapor deposition (CVD) coated tool insert. It was found that cutting speed is the most significant factor for surface roughness and flank wear. Ciftci et al. [22] analyzed the influence austenitic stainless steels by using coated cemented carbide tools under different cutting speed. The results showed that the cutting speed affect the surface roughness of the machined parts. Cryo-processing cooling investigation by Reitz et al. [23] exposed the material to extremely low temperatures to change their mechanical and physical properties. It was observed that reducing the amount of retained austenite; this improves on wear resistance, dimensional stability, electrical and thermal conductivity, and hardness. Da Silva et al. [24] performed a cryogenic treatment on high steel tool to indicated micro structural changes in the material that can impact tool life and productivity significantly. It was found that tool life changes from $92 \%$ to $81.7 \%$ when utilizing the cryogenically treated HSS tool in the industry. Dhar et al. [28] investigated on minimization of cutting. The results revealed that the reduction in tool wear and surface roughness by minimum quality lubricant and it was observed that reduction in tool chip temperature and work-tool interface. From the literature, it was found that most of the studies are restricted to the studies of cryogenic treated carbide cutting tool in terms of optimization of cutting parameters such as tool wear, surface roughness and hardness. However, the available results in the literature related to wear, surface roughness and optimization of cutting parameters were not providing detailed results. Thus, the present study is aimed at investigating the performance of a cryogenic treated carbide cutting tool for different cutting parameters. The test results were validated with Taguchi technique. In addition, a confirmation test was performed to validate the experimental results.

\section{EXPERIMENTAL DETAILS}

\section{Experimental Methodology}

The Machining work carried on AISI304 Steel work piece having a specification of 30mm diameter, length $150 \mathrm{~mm}$ and having chemical composition of $0.085 \% \mathrm{C}, 18 \% \mathrm{Cr}, 66.34 \% \mathrm{Fe}, 2 \%$ $\mathrm{Mn}, 8 \% \mathrm{Ni}, 0.045 \% \mathrm{P}, 0.035 \mathrm{~S}, 1 \% \mathrm{Si}$. The length / diameter proportion was considered during the experimentation in order to meet the ISO 3685. In the course of experimentation, a total of 9 work piece were utilized to predict the tool life. The machining operation of the cutting tool insert was performed using CNC lathe (ACE jobber CNC Lathe) having a maximum speed of 4000rpm, maximum turning diameter $290 \mathrm{~mm}$, length $400 \mathrm{~mm}$ and chuck size $200 \mathrm{~mm}$. The machining experiments were performed for different cutting speed, depth of cut, and feed rate. The cutting speed was done for $100 \mathrm{~m} / \mathrm{min}, 120 \mathrm{~m} / \mathrm{min}, 140 \mathrm{~m} / \mathrm{min}$ and depth of cut was done for $0.5 \mathrm{~mm}, 1.0 \mathrm{~mm}$ and $1.5 \mathrm{~mm}$. While feed rate $0.1 \mathrm{~mm} / \mathrm{rev}, 0.15 \mathrm{~mm} / \mathrm{rev}$ and $0.2 \mathrm{~mm} / \mathrm{rev}$. Material characterization of the carbide inserts were examined by using scanning electron microscope (SEM) combined with micro hardness analyzer. Hardness test was conducted for both cryogenic treated and untreated 
inserts by using Vickers hardness testing machine with a load of 50Kgf impressed on the tool insert. With a dwell time, $15 \mathrm{sec}$ and the average of the hardness were evaluated. The improved surface structure due to cryogenic treatment was measured with the use of surface measuring instrument SJ210 average value were evaluated. The flank wear caused due to rubbing action between cutting tool and workpiece was measured in the experiment. The maximum flank wear test of the insert was measured at a time step of $5 \mathrm{~min}$ as per ISO 3685 of 1993[25-26].

In the present work, examined the cryogenic treatment of a tungsten carbide cutting tool and compared their results with untreated carbide cutting tool. An optimization test was carried out using Taguchi L9 array. A Minitab Statistical 16 Software trial version was used for Taguchi Design. Various mechanical tests were performed for both cryogenic treated and untreated insert for comparison. In the process of cryogenic, the temperature was lowered from ambient conditions to $176^{\circ} \mathrm{C}$ in the beginning at a rate of $-1{ }^{\circ} \mathrm{C} / \mathrm{min}$ and was soaked maintaining the same temperature for 36 hours. The temperature was brought back to its ambient conditions at a rate of $-1^{\circ} \mathrm{C} / \mathrm{min}$. The experiment was carried out for various parameters such as cutting speed, feed rate, and depth of cut. In the current experimental set up, PVD coated tungsten carbide insert of ISO standard TNMG160408GS PC8110 was used. The cutting tool insert thickness was $4.76 \mathrm{~mm}, 0.8 \mathrm{~mm}$ nose of triangular shape was used for machining.

\section{Design of Experiments}

The optimization of the experimental results was performed by using Taguchi approach with the L9 orthogonal array to optimize the cutting parameters and to determine the optimal level of process parameters for optimizing the quality of surface finish and tool wear of AISI304 material. In this three different cutting levels were considered for each parameter as shown in Table 1 . The Table 2 demonstrates the response table for tool wear and surface roughness.

Table 1. Selection of cutting parameters for different levels.

\begin{tabular}{llll}
\hline Parameters & Level-1 & Level-2 & Level-3 \\
\hline Cutting speed, (m/min) & 100 & 120 & 140 \\
Depth of Cut, (mm) & 0.5 & 1 & 1.5 \\
Feed, (mm/rev) & 0.1 & 0.15 & 0.2 \\
\hline
\end{tabular}

Table 2. Response Table for different cutting parameter obtained from Taguchi L9.

\begin{tabular}{llllll}
\hline $\begin{array}{l}\text { Test } \\
\text { No. }\end{array}$ & $\begin{array}{l}\text { Cutting } \\
\text { Speed, } \\
(\mathrm{m} / \mathrm{min})\end{array}$ & $\begin{array}{l}\text { Depth of } \\
\text { Cut,(mm) }\end{array}$ & $\begin{array}{l}\text { Feed, } \\
(\mathrm{mm} / \mathrm{rev})\end{array}$ & $\begin{array}{l}\text { Flank } \\
\text { wear,(mm) }\end{array}$ & $\begin{array}{l}\text { Surface Roughness, } \\
\text { (microns) }\end{array}$ \\
\hline 1 & 100 & 0.5 & 0.10 & 0.217 & 2.123 \\
2 & 100 & 1.0 & 0.15 & 0.17 & 1.11 \\
3 & 100 & 1.5 & 0.20 & 0.26 & 2.59 \\
4 & 120 & 0.5 & 0.15 & 0.33 & 0.79 \\
5 & 120 & 1.0 & 0.20 & 0.51 & 2.312 \\
6 & 120 & 1.5 & 0.10 & 0.60 & 1.75 \\
7 & 140 & 0.5 & 0.20 & 0.34 & 1.54 \\
8 & 140 & 1.0 & 0.10 & 0.61 & 0.902 \\
9 & 140 & 1.5 & 0.15 & 0.52 & 1.12 \\
\hline & & & & Avg. Tool & Avg. surface \\
& & & & Wear $=0.395$ & roughness $=1.581$ \\
\hline
\end{tabular}




\section{RESULTS AND DISCUSSION}

\section{Flank Wear Study}

The flank wear produced during the experimental operation on stainless steel AISI304 was observed in terms of tool wear for coated and uncoated cutting tool insert frequently for varying time. In the present wear study, it was observed that the tool wear was occurred due to various factors that include rubbing action between the cutting tool and work piece, enormous amount of heat generation at the tool tip and excessive generation of chips during machining operation. These factors cause a premature failure of the cutting tool. The flank wear growth during the machining operation was observed for three different speed rates. The flank wear enhanced was noticed for increase in speed. Figures 1, 2 and 3 shows wear resistance, at different cutting speed, having the constant depth of cut and feed rate for cryogenic treated and untreated inserts. From the graph shown in Figure 1 at a cutting of speed of $100 \mathrm{~m} / \mathrm{min}$, depth of cut $0.5 \mathrm{~mm} \&$ feed rate $0.1 \mathrm{~mm}$ $\mathrm{rev} / \mathrm{min}$ the treated insert resists maximum wear than untreated inserts. As cutting speed increase, the wear resistant was found to be more in cryogenic treated compared to untreated insert as demonstrated in the Figures 1,2 and 3. The presence of coating layer over the cutting tool, resist initial wear due to machining operation because of improved surface roughness and strengthen the surface resistance. Hence the initial wear produced for both were seen to be slow and increased rapidly with time. This is due to the presence of coating layer over the cutting tool. Wear tests were conducted for all three cutting speed, cryogenic insert resist wear more effectively due to enhanced thermal and other mechanical properties, Hence, enhance tool life was observed for cryogenic treated inserts than untreated insert. However, an increased wear was noticed for the untreated cutting tool for all the three different cutting speed. The gain in hardness and improved surface roughness due to cryogenic treatment upgrade the tool life of the cutting tool up to some extent.

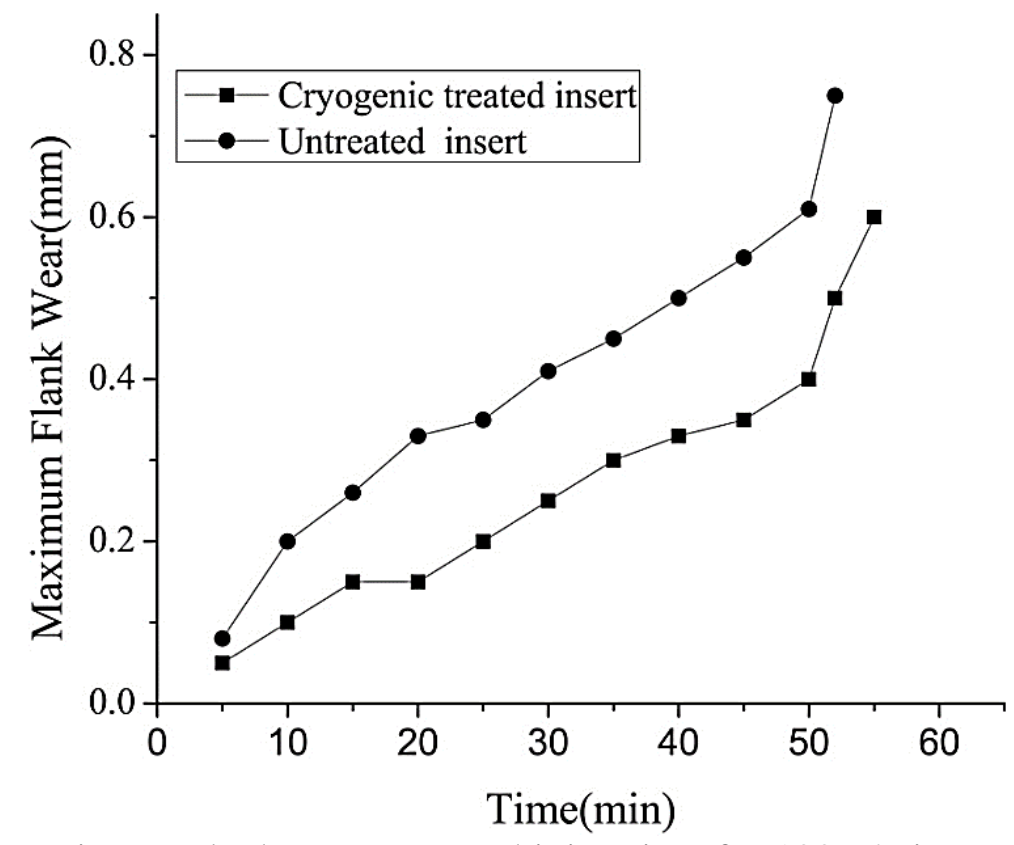

Figure 1. Maximum Flank wear vs. Machining time for $100 \mathrm{~m} / \mathrm{min}$ cutting speed. 


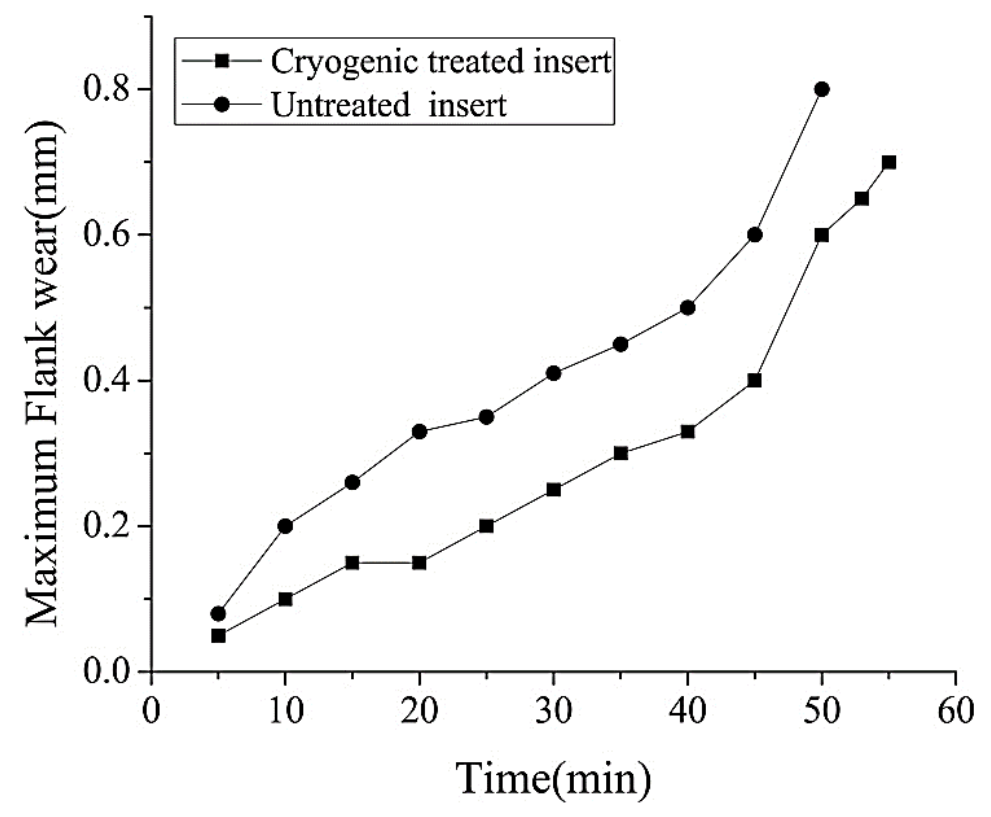

Figure 2. Maximum Flank wear vs. Machining time for 120m/min cutting speed.

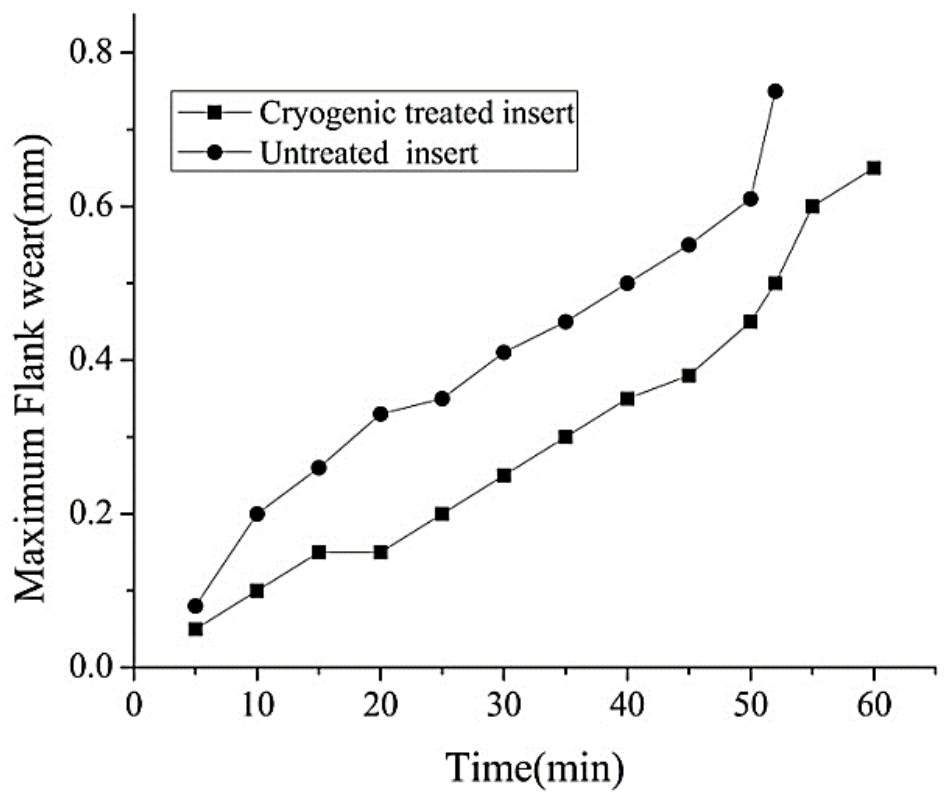

Figure 3. Maximum Flank wear vs. Machining time for $140 \mathrm{~m} / \mathrm{min}$ cutting speed

An enhanced tool life was noticed in terms of tool wear due to cryogenic treatment of tungsten carbide cutting tool. The cryogenically treated cutting tool performs better under discontinuous machining condition at higher cutting speed. The results also demonstrate that an improved wear resistance of cryogenic treated insert was found in comparison with untreated tool insert under deep cryogenic treatment for different holding times on machining AISI 304 steel. The Table 3 reveals a tool life (min) for cryogenic treated tool insert and untreated tool insert. 
Table 3. Tool life for different cutting speed for both cryogenic treated and untreated cutting tool.

\begin{tabular}{llll}
\hline \multirow{2}{*}{ Machining Condition } & \multicolumn{3}{l}{ Tool life for different cutting speed (min) } \\
\cline { 2 - 4 } & $100(\mathrm{~m} / \mathrm{min})$ & $120(\mathrm{~m} / \mathrm{min})$ & $140(\mathrm{~m} / \mathrm{min})$ \\
\hline Cryogenic treated cutting tool & 55 & 49 & 46 \\
Untreated cutting tool & 50 & 44 & 40 \\
\hline
\end{tabular}

\section{Microscopic Study of Tool Wear}

The Figure 4 and Figure 5 showed the variety of normal flank wears at each exploratory run for cryogenic treated and untreated cutting tool inserts. It is observed that the utilization of a cryogenic treated cutting insert helps in reducing the flank wear strikingly. The flank wear was noticed minimum in the range of cutting speed $(100-140 \mathrm{~m} / \mathrm{min})$, depth of cut $(0.5 \mathrm{~mm})$, and feed rate $(0.1 \mathrm{~mm} \backslash \mathrm{rev})$ in the present investigation. The SEM images demonstrate a minimum wear in case of cryogenic treated cutting insert, however untreated insert observed to be more in correlation with the cryogenic treated cutting tool insert.
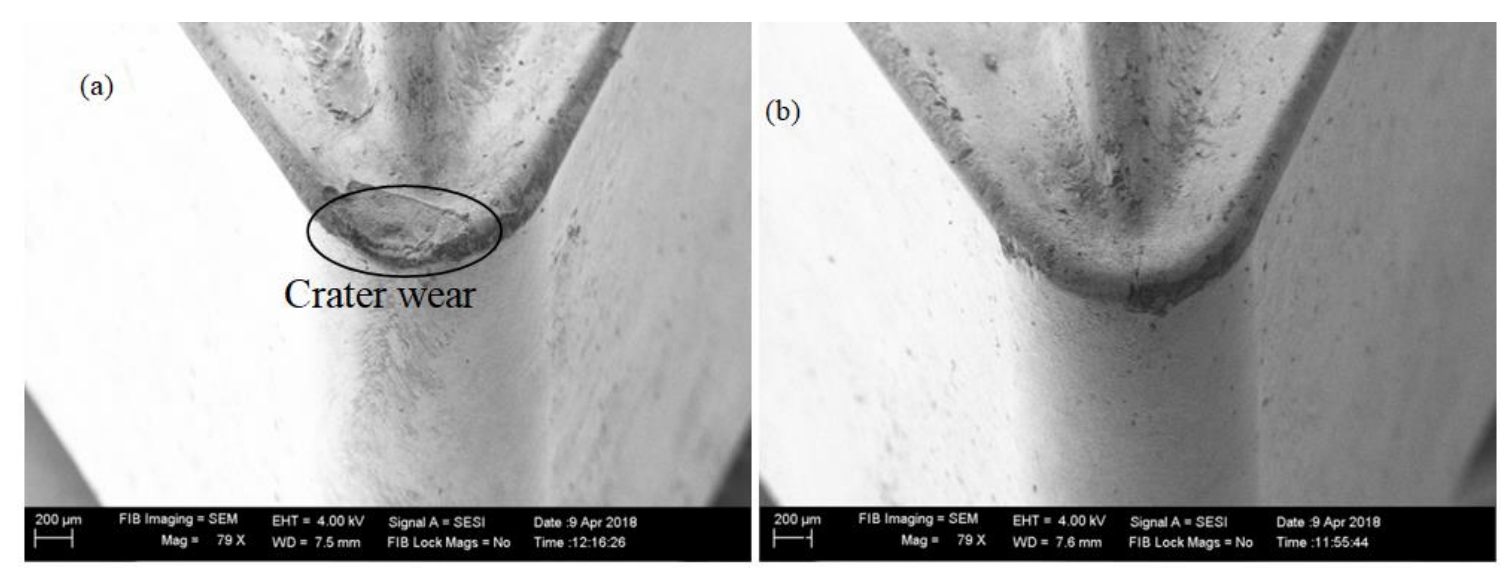

Figure 4. Microscopic image of wear observed at cutting speed $140 \mathrm{~m} / \mathrm{min}$, depth of cut $0.5 \mathrm{~mm}$ and feed rate $0.1 \mathrm{~mm} / \mathrm{rev}$ for(a) untreated cutting tool insert and (b) cryogenic treated cutting tool insert.
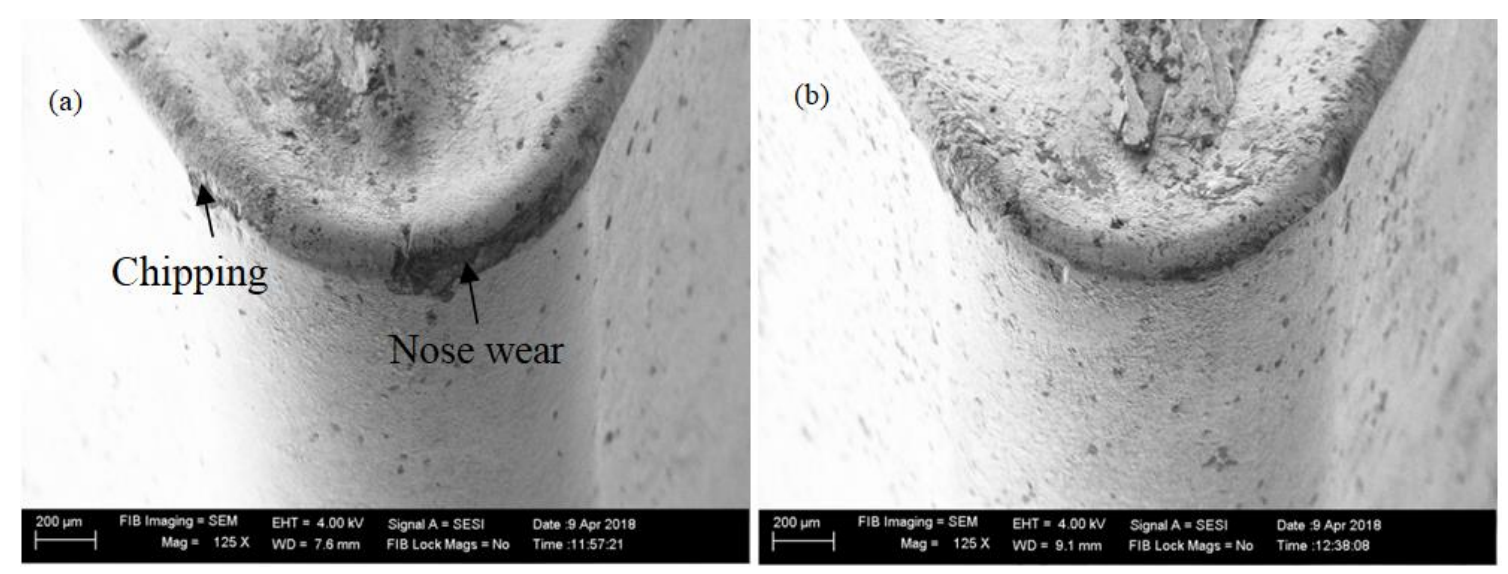

Figure 5. Microscopic image of wear observed at cutting speed $100 \mathrm{~m} / \mathrm{min}$, depth of cut $0.5 \mathrm{~mm}$ and feed rate $0.1 \mathrm{~mm} / \mathrm{rev}$ for(a) untreated cutting tool insert and (b) cryogenic treated cutting tool insert.

The use of cryogenic treated cutting tool insert was found to be better at higher cutting speed of $140 \mathrm{~m} / \mathrm{min}$ for machining AISI 304 material. This is due to the reduction in flank and crater wear at incredible extent. From the figure, it is seen that the crater wear is significantly reduced in case of 
for cryogenic treated cutting tools. The width of crater wear was found to be less for cryogenic treated cutting tool than the untreated one as shown in Figure $4 \mathrm{a}$ and $4 \mathrm{~b}$. The crater wear on the rake surface and significant impacts were missing (Figure 4b) for higher cutting speeds in comparison with untreated cutting tool. The fracture and chipping are found to be seen less in the case of cryogenic treated cutting tool. Minimized built-up edges were observed due to cryogenic treatment even at higher cutting speed.

\section{Morphological Study of Cryogenic Treated and Untreated Insert}

The SEM microstructure analysis was carried out for both cryogenic treated and untreated insert as shown in Figure 6a and Figure 6b. The analysis was conducted according to the ASTM B6572003standard method [26]. The general phases were observed in Tungsten carbide $\alpha$ phase indicates tungsten carbide, $\beta$ phase indicated Cobalt binder, $\gamma$ phase indicates Carbides of cubic lattice and Eta $\eta$ phase multiple carbides tungsten. The increased concentration of carbide particle was seen. The enhanced Eta $\eta$-phase was obtained due to long exposure of the insert to a lower temperature. The similar micro structure phases were obtained in $[1,2]$. From the SEM image, an increase in the eta phase is observed in Figure 6a. The increase in eta phase improves wear resistance because of the densely packed carbides in the structure due to longer exposure of the cutting tool to a lower temperature [9].

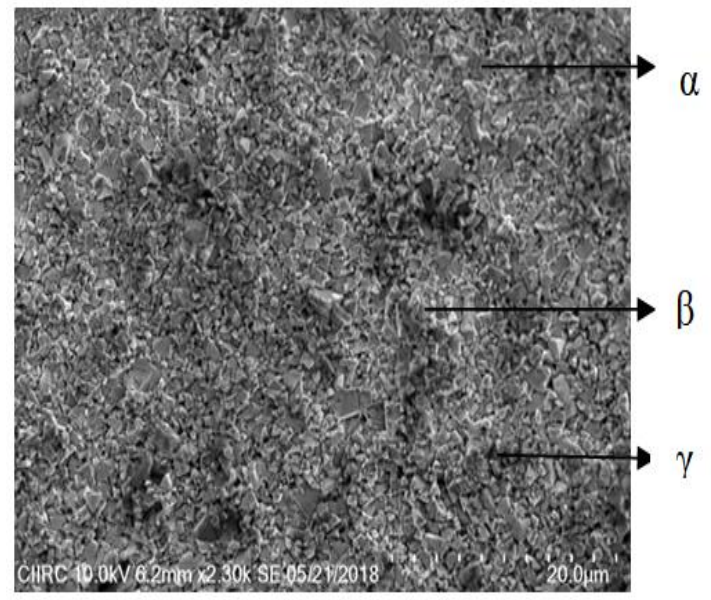

(a)

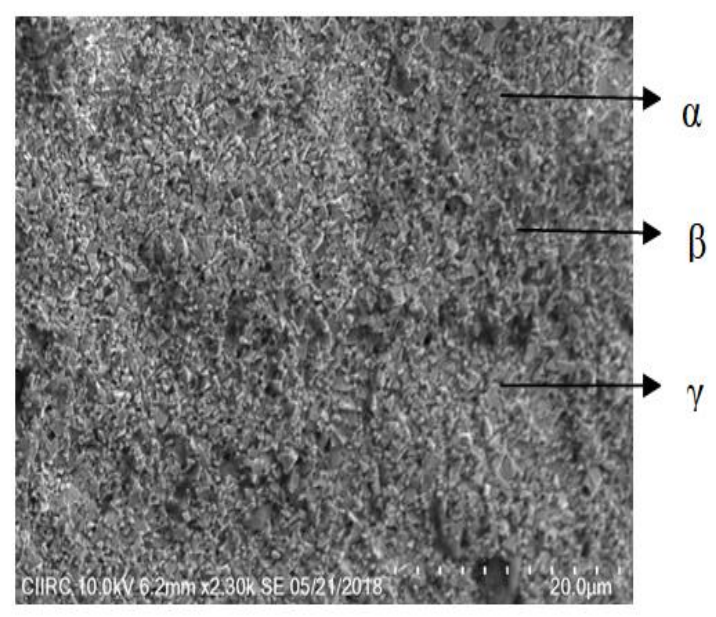

(b)

Figure 6.SEM image (a) Cryogenic cutting tool insert (b) Untreated cutting tool insert.

\section{Hardness Test}

In the present work, Vickers hardness test of the carbide cutting tool was analyzed. The effect of cryogenic treatment on carbide tool inserts was examined and compared their results with untreated cutting tool as shown in Figure 7. An increase in hardness rate is obtained due to improved micro structural and phase change of a material. The cutting tools which were cryogenically treated demonstrated further increment in hardness because of the higher chromium carbide rate. The enhanced hardness was seen for deep cryogenically treated tungsten carbide tool due to increase in the Eta phase, the carbon percentage increases the hardness over the surface of the insert. The Eta phase was found multiple carbides results in increase in hardness. The growth in the hardness was seen to be approximately $4 \%$ after cryogenic treatment. The improved hardness of the cryogenic treated insert was observed due to cobalt densification by [1]. 


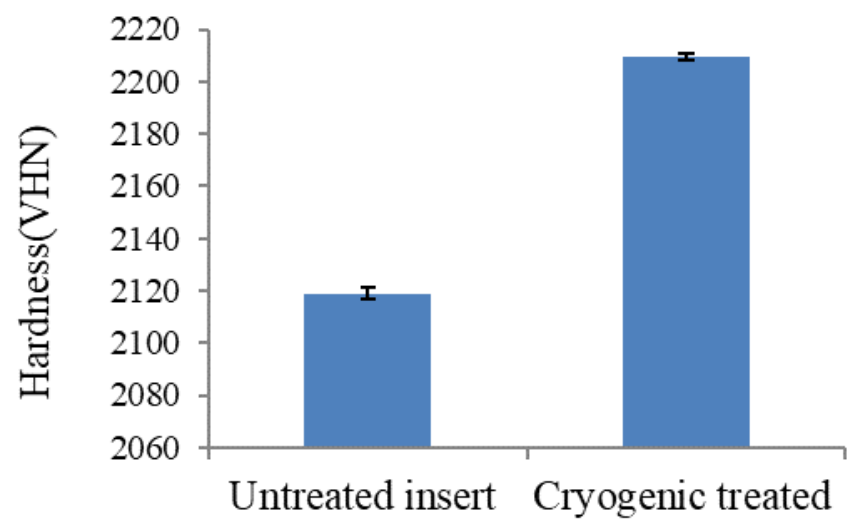

Figure 7. Hardness values at cryogenic treated and untreated insert.

\title{
Surface Roughness
}

Surface roughness is an important parameter to decide the quality of the machined parts and life of the cutting tool. The irregularity of machined surface is output of the machining process including the selection of cutting tool, feed rate and depth of cut and also depend on different coolant were in decrease the cutting temperature. The Figure 8 shows the surface roughness of cryogenic treated and untreated cutting tool for different cutting speed of machining time 10min. An increase in the cutting speed decrease in surface roughness is observed. Also it was noticed that cryogenic treatment inserts show lower surface roughness in comparison with untreated insert. Reddy et al [1] claimed due to increase in the thermal conductivity in the cryogenic treated surface roughness reduces. Dhar [27] also reported cryogenic cooling reduces the surface roughness.

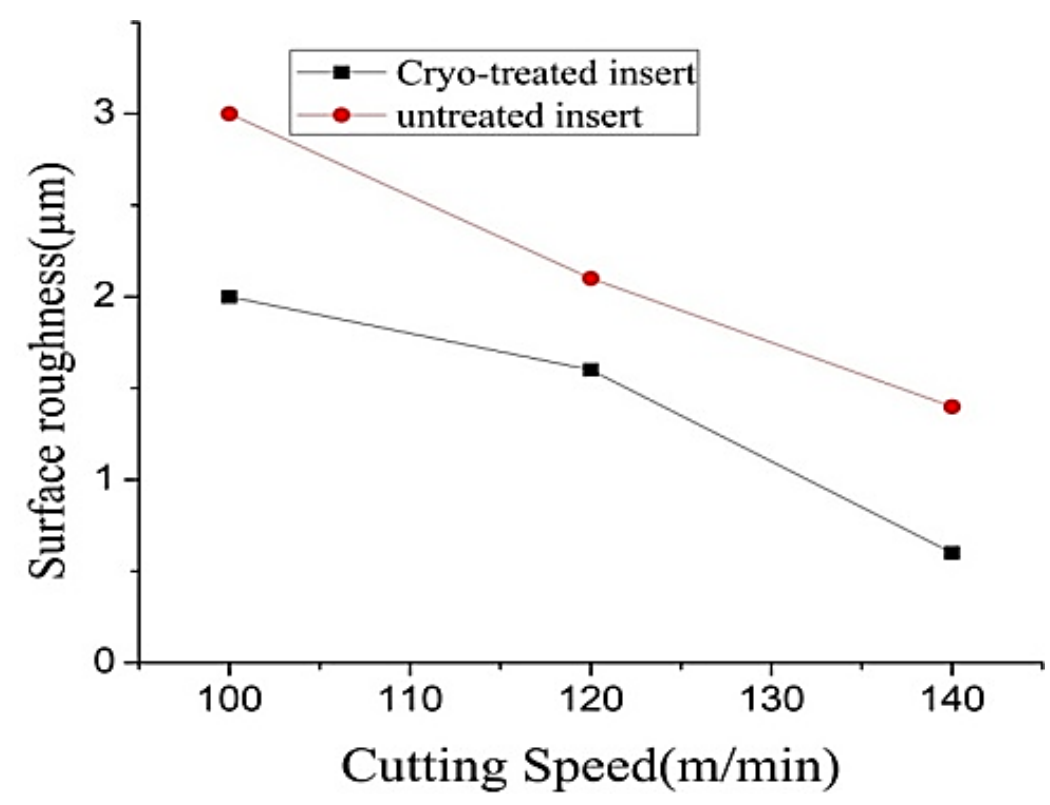

Figure 8. Variation of surface roughness for different cutting speed.

\begin{abstract}
ANOVA for Tool Wear
In this present work ANOVA method was deployed in order to find out the essential factor which affects the performance measures. The Table 4 demonstrates that the cutting speed is the most significant affecting parameter among others in terms of tool wear. A maximum contribution for the tool failure is obtained for cutting speed and a minimize contribution was obtained for feed rate. The Table 5 demonstrates that the feed rate is the most significant affecting parameter among others
\end{abstract}


in terms of surface roughness. The analysis was conducted for the significance level of $\alpha=0.05$ i.e. for a confidence level of $95 \%$ if the p-value less than 0.05 are considered.

Table 4. Analysis of variance for tool wear (ANOVA).

\begin{tabular}{ccccccc}
\hline Source & DOF & Seq.SS & MS & F & P & $\begin{array}{c}\% \\
\text { Contribution }\end{array}$ \\
\hline Cutting speed & 2 & 0.145231 & 0.072615 & 44.95 & 0.022 & 65.52 \\
Depth of cut & 2 & 0.045951 & 0.022975 & 14.22 & 0.066 & 20.72 \\
Feed rate & 2 & 0.030471 & 0.015235 & 9.43 & 0.096 & 13.74 \\
Residual Error & 2 & 0.003231 & 0.001615 & & & \\
Total & 8 & 0.224884 & & & & \\
\hline
\end{tabular}

DOF-Degrees of freedom, Seq.SS-Sequential sum of squares, MS-Mean sum of Squares

\section{Main Effect Graphs for Tool Wear and Surface Roughness}

The ANOVA analysis was made with the help of the MINITAB16 statistical tool to study the cutting parameters (cutting speed, depth of cut and feed rate) and the main effect plots on tool wear and surface roughness were analyzed as shown in Figures 7 and 8 respectively. The main effect graphs showed the variation of individual response with the three cutting parameters. In the main effect graphs $\mathrm{x}$-axis indicates the value of cutting parameters at three levels and the $\mathrm{y}$-axis indicates the response value. The main effect graphs were used for finding the optimum levels of tool wear and surface roughness. Figure 9 shows the main effect graphs for tool wear as tool wear increase with increase with cutting speed; on the other hand, increase in the feed rate will decrease in tool wear. However, increase in depth of cut there is an increase in tool wear. Maximum tool wear shown at the $1.5 \mathrm{~mm}$ depth of cut. Similarly, from Figure 10 as cutting speed increase surface roughness decrease on the other hand increase in feed rate will increase in the surface roughness. From Figure 9 optimum value of tool wear Cutting speed of $110 \mathrm{~m} / \mathrm{min}$ [level 1] Depth of cut 0.5 $\mathrm{mm}$ [level 1] Feed rate of $0.15 \mathrm{~mm} / \mathrm{rev}$ [level 2] From Figure 10 low value of surface roughness was obtained at Cutting speed of $140 \mathrm{~m} / \mathrm{min}$ [level 3] Depth of cut $1.0 \mathrm{~mm}$ [level 2] Feed rate of $0.15 \mathrm{~mm} / \mathrm{rev}$ [level2].
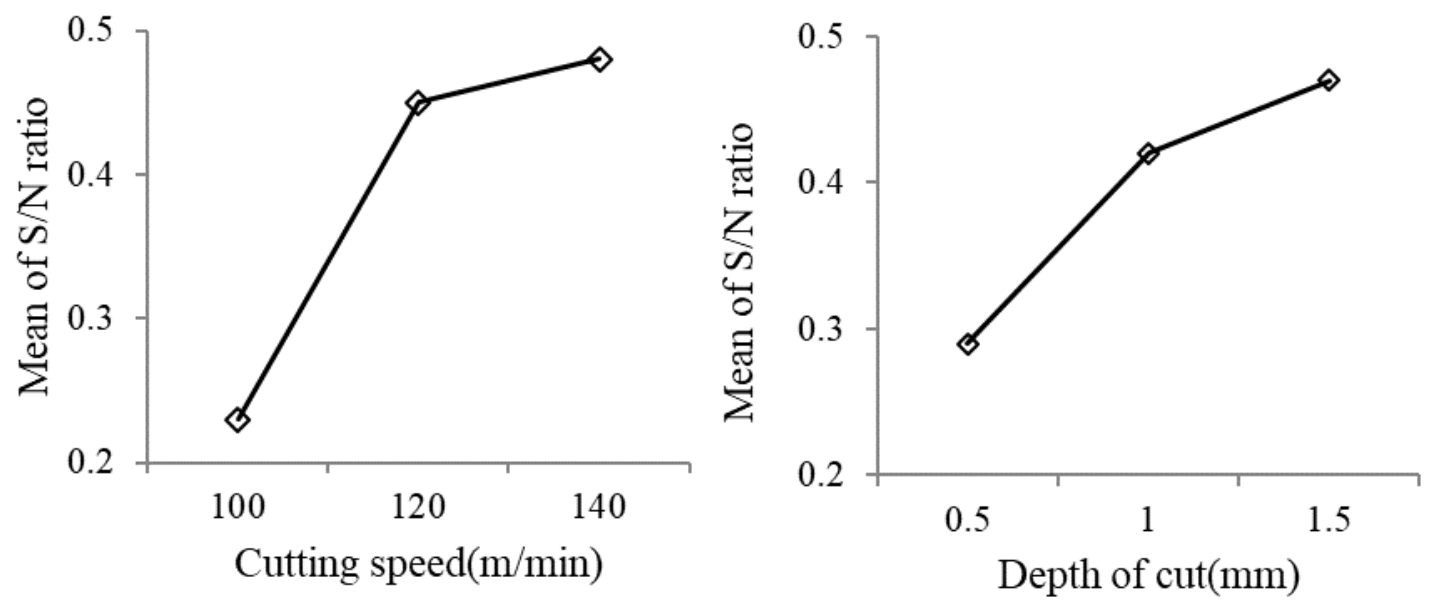


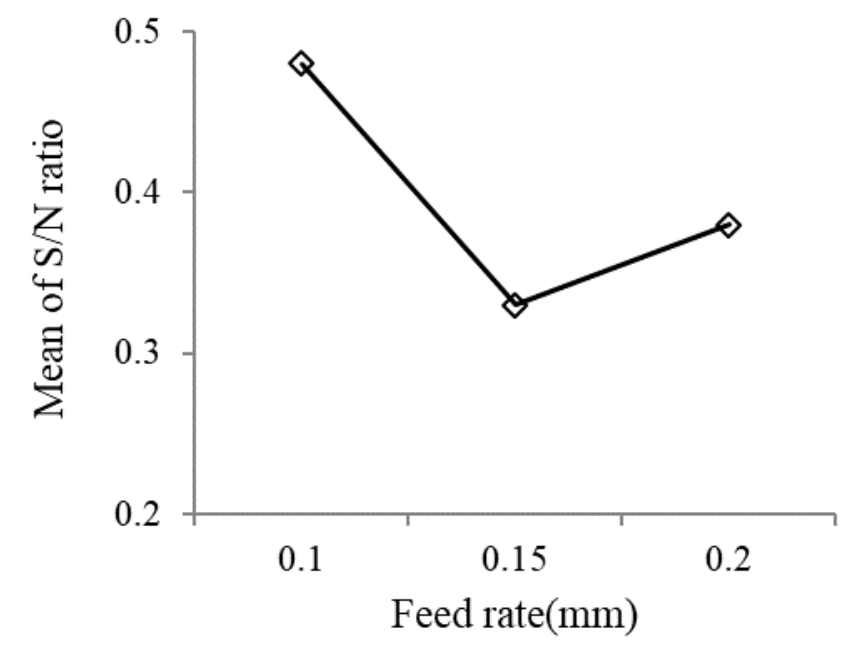

Figure 9. Main effect plot for tool wear.
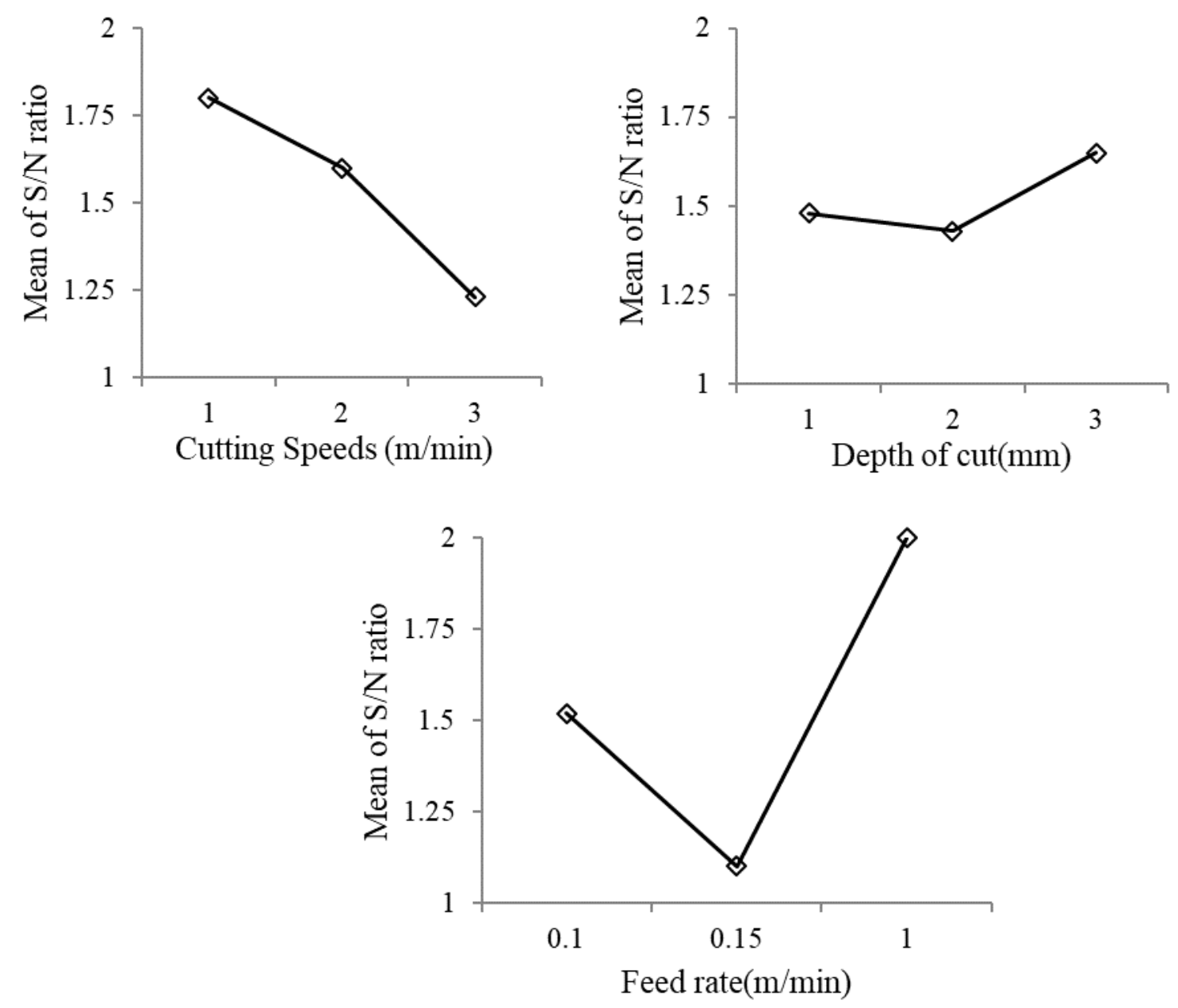

Figure 10. Main effect plot for surface roughness.

\section{Optimal Design}

An optimization of the tool wear and surface roughness is adopted in the present study considering from mean response value from Table 2. The predicted values for surface roughness and tool wear were evaluated by using the optimum levels of cutting speed, feed rate and depth of cut for surface roughness and tool wear.

Tool wear for cutting speed and depth of cut is given by equation Equation (1). 


$$
\mu \text { Tool Wear }=\mathrm{V} 1+\mathrm{D} 1-\mathrm{Avg}_{\mathrm{Tw}}
$$

The values of $\mathrm{V}_{1}$ and $\mathrm{D}_{1}$ were taken from Table 5 and average tool wear was considered to be 0.395 from the Table 2 .

$$
\mu \text { Tool Wear }=0.1157
$$

Confidence interval (CI) for tool wear was calculated using 00Equation (2).

$$
\mathrm{CI}=\frac{\sqrt{\mathrm{F} 95 \% 1_{z} \text { DOF error X Verror }}}{\mathrm{D}_{\mathrm{eff}}}
$$

When $\mathrm{\eta}_{\text {eff }}$ is calculated using equation Equation (3).

$$
\begin{gathered}
\mathrm{\eta}_{\text {eff }}=\frac{\text { Number of trials }}{1+\mathrm{DOF} \text { associated to that level }} \\
=\frac{9}{1+2+2}=1.8
\end{gathered}
$$

From F-Table F95\%1,4=7.71

From Table 4 we have, $\mathrm{V}$ error $=0.001615$

$$
\mathrm{CI}=\sqrt{\frac{7.71 \times 0.001615}{1.8}}=0.083
$$

The predicted optimal range of tool wears at $95 \%$ confidence level is given by Equation (4).

$$
\begin{aligned}
& 0.1157-0.083 \leq \mu \text { Tool Wear } \leq 0.1157+0.083 \\
& 0.0327 \leq \mu \text { Tool Wear } \leq 0.1987
\end{aligned}
$$

Surface roughness of cutting speed and feed rate is given by Equation (5)

$$
\mu_{\mathrm{Sa}}=\mathrm{V} 3+\mathrm{F} \cdot \mathrm{R} 2-\mathrm{Avg}_{\mathrm{SR}}
$$

The values of $\mathrm{V}_{3}$ and F.R2 were taken from Table 6 and average surface roughness was considered to be 1.581 from the Table 2 .

$$
\mu_{\mathrm{Sa}}=1.187+1.007-1.581=0.613
$$

Confidence interval (CI) for surface roughness was calculated using- Equation (6).

$$
\mathrm{CI}=\frac{\sqrt{\mathrm{F} 95 \%, 1, \text { DOF error X Verror }}}{\mathrm{I}_{\mathrm{eff}}}
$$

When $\eta_{\text {eff }}$ is calculated using Equation (7)

$$
\begin{aligned}
& \text { Where } \eta_{\text {eff }}=\frac{\text { Number of trials }}{1+\text { DOF associated to that level }} \\
& =\frac{9}{1+2+2}=1.8
\end{aligned}
$$


F95\%1,4=7.71(From F-table), $V_{\text {error }}=0.1649$ (from Table 5)

$$
\mathrm{CI}=\sqrt{\frac{7.71 \times 0.1649}{1.8}}=0.840
$$

The predicted optimal range of surface roughness at $95 \%$ confidence level is given by Equation (8).

$$
\begin{gathered}
0.613-0.840 \leq \mu_{\mathrm{Sa}} \leq 0.613+0.840 \\
-0.227 \leq \mu_{\mathrm{Sa}} \leq 1.453
\end{gathered}
$$

Table 5. Means response table for tool wear.

\begin{tabular}{llll}
\hline Level & Cutting speed(V) & Dept of cut(D) & Feed rate(FR) \\
\hline 1 & 0.2157 & 0.2957 & 0.4757 \\
2 & 0.4800 & 0.4300 & 0.3400 \\
3 & 0.4900 & 0.4600 & 0.3700 \\
Delta & 0.2743 & 0.1643 & 0.1357 \\
\hline Rank & 1 & 2 & 3 \\
\hline
\end{tabular}

Table 6. Means response table for surface roughness.

\begin{tabular}{llll}
\hline Level & Cutting speed(V) & Dept of cut(D) & Feed rate(FR) \\
\hline 1 & & & \\
2 & 1.941 & 1.484 & 1.592 \\
3 & 1.617 & 1.441 & 1.007 \\
Delta & 1.187 & 1.820 & 2.147 \\
\hline Rank & 0.754 & 0.379 & 1.141 \\
\hline
\end{tabular}

Where $\mathrm{SR}_{\mathrm{opt}}$ and TWopt denote the predicted value of surface roughness and the tool wear in optimum condition respectively. As per the Equations (9) \& (10), it was calculated that optimum value of SRopt $=0.473 \mu \mathrm{m}$ and TWopt $=0.0614 \mathrm{~mm}$.

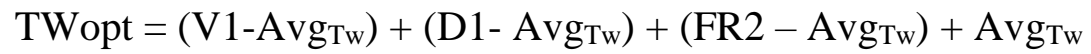

$$
\begin{aligned}
& \text { SRopt }=\left(\mathrm{V} 3-\mathrm{Avg}_{\mathrm{SR}}\right)+\left(\mathrm{D} 2-\mathrm{Avg}_{\mathrm{SR}}\right)+\left(\mathrm{FR} 2-\mathrm{Avg}_{\mathrm{SR}}\right)+\mathrm{Avg}_{\mathrm{SR}}
\end{aligned}
$$

\section{Confirmation Test}

Confirmation test was carried out using the optimum surface roughness levels $(3,2,2)$ and tool wear $(1,1,2)$ selected. Among various experimental parameters, the experimental value of surface roughness value is $0.421 \mu \mathrm{m}$ and optimum roughness values using the Taguchi technique were calculated by estimating $0.473 \mu \mathrm{m}$. While for the tool wear is $0.0560 \mathrm{~mm}$ obtained from the experimental data. The tool wear values using the Taguchi method were calculated by estimating $0.0614 \mu \mathrm{m}$. The results demonstrate an error of $8.79 \%$ and $10.9 \%$ error between experimental value and predicted value for wear and surface roughness respectively. Hence the the predicted and the experimental surface roughness values were found to be in good agreement. The confirmation test results showed optimization correctly. 


\section{CONCLUSION}

This research paper compared and discussed on the investigation of cryogenic treated cutting tool insert and untreated cutting tool insert. The following conclusions were drawn based on the experiments and statistical study.

1. The tool wear resistance was more effective in cryogenically treated tungsten carbide inserts due to enhanced thermal and other mechanical properties, which results in enhancing the tool life of the cutting inserts up to some extent for all the three cutting speed tested. An increased wear was noticed in the untreated cutting tool as compared with Cryogenic treated one. It was observed from the results that the utilization of a cryogenically treated cutting tool insert helps in decreasing the flank wear strikingly.

2. The enhanced in the Eta phase, the carbon percentage increased. The improved hardness on the top surface of the insert, the Eta phase indicates multiple carbides. Hence the gain in hardness and improved surface roughness was achieved which upgrade the tool life. The growth in the hardness approximately $4 \%$ after Cryogenic treatment.

3. The surface roughness diminishes with increase in cutting speed. With cryogenic treated embeds in correlation with untreated tool at all cutting rates.

4. The design of experiment in the current study proposed optimum levels for cutting parameters. The errors between predicted and experimental results were found to be $8.79 \%$ for tool wear and $10.9 \%$ for surface roughness.

\section{REFERENCES}

[1] Sreerama Reddy TV, Sornakumar T, Venkatarama Reddy M, Venkatram R. Machining performance of low temperature treated P-30 tungsten carbide cutting tool inserts. Cryogenics. 2008;48:458-461.

[2] Khan A, Maity K. Comparative study of some machinability aspects in turning of pure titanium with untreated and cryogenically treated carbide inserts. Journal of Manufacturing Processes. 2017;28:272-284.

[3] Akhbarizadeh A, Shafyei A, Golozar MA. Effects of cryogenic treatment on wear behavior of D6 tool steel. Materials and Design. 2009;30:3259-3264.

[4] Amini K, Nategh S, Shafyei A. Influence of different cryotreatments on tribological behavior of 80CrMo12 5 cold work tool steel. Materials and Design. 2010;31:4666-4675.

[5] Bordin A, Bruschi S, Ghiotti A, Bariani PF. Analysis of tool wear in cryogenic machining of additive manufactured Ti6Al4V alloy. Wear. 2015;328-329:89-99.

[6] Das D, Dutta AK, Ray KK. Correlation of microstructure with wear behaviour of deep cryogenically treated AISI D2 steel. Wear. 2009; 267:1371-1380.

[7] Dhananchezian, Pradeep Kumar M. Cryogenic turning of the Ti-6Al-4V alloy with modified cutting tool inserts. Cryogenics. 2011;51:34-40.

[8] Özbek NA, Çiçek A, Gülesinc M, Özbek O. Effect of cutting conditions on wear performance of cryogenically treated tungsten carbide inserts in dry turning of stainless steel. Tribology International 2015.

[9] Özbek NA, Çiçek A, Gülesin M, Özbek O. Investigation of the effects of cryogenic treatment applied at different holding times to cemented carbide inserts on tool wear. International Journal of Machine Tools \& Manufacture. 2014;86:34-43.

[10] Yong AYL, Seah KHW, Rahman M. Performance evaluation of cryogenically treated tungsten carbide tools in turning. International Journal of Machine Tools \& Manufacture. 2006;46:2051-2056. 
[11] Seah KH., Rahman M. Yong KH, Performance evaluation of cryogenically treated tungsten carbide cutting tool inserts, Proceedings of the Institution of Mechanical Engineers. Part B: Journal of Engineering Manufacture. (2003); 217:29:29-43.

[12] Vadivel K. Rudramoorthy R. Performance analysis of cryogenically treated coated carbide inserts. Int J Adv Manuf Technol. (2009);42:222-232.

[13] Mahdavinejadand RA, Saeedy S. Investigation of the influential parameters of machining of AISI 304 stainless steel. Indian Academy of Sciences. 2011;36: 963-970.

[14] Akıncıoğlu, Gökkaya H, Uygur İ. The effects of cryogenic-treated carbide tools on tool wear and surface roughness of turning of Hastelloy C22 based on Taguchi method. Int J Adv Manuf Technol. 2016;82:303-314.

[15] Rashid WB, Goel S, Davim JP, Joshi SN. Parametric design optimization of hard turning of AISI 4340 steel (69 HRC). Int J Adv Manuf Technol. 2016;82:451-462.

[16] Kirby ED, Zhang Z. Joseph C. Chen. Chen J. Optimizing surface finish in a turning operation using the Taguch parameter design method. Int J Adv Manuf Technol. 2006;30:1021-1029.

[17] Hasçalık A, Çaydaş U. Optimization of turning parameters for surface roughness and tool life based on the Taguchi method. Int J Adv Manuf Technol. 2008;38:896-903.

[18] Cakırog lu R, Acır A. Optimization of cutting parameters on drill bit temperature in drilling by Taguchi method. Measurement. 2013;46:3525-3531.

[19] Thakur D, Ramamoorthy B, Vijayaraghavan L. Influence of different post treatments on tungsten carbide-cobalt inserts. Materials Letters.2008; 62:4403-4406.

[20] Gill SS, Singh R, Singh H, Singh J. Wear behaviour of cryogenically treated tungsten carbide inserts under dry and wet turning conditions. International Journal of Machine Tools \& Manufacture. 2009;49:256-260.

[21] Kaladhar M, Subbaiah KV, Rao CHS. Optimization of surface roughness and tool flank wear in turning of AISI 304 austenitic stainless steel with CVD coated tool. Journal of Engineering Science and Technology.2013;8:165 - 176.

[22] Ciftci I. Machining of austenitic stainless steels using CVD multi-layer coated cemented carbide tools. Tribology International. (2006);39:565-569.

[23] Reitz W, Pendray J. cryoprocessing of materials. A review of current status. Materials and Manufacturing Processes. 2001;16:829-840.

[24] Da Silva FJ, Franco SD, Machado ÁR, Ezugwu EO, Souza AM. Performance of cryogenically treated HSS tools. Wear. 2006;261:674-685.

[25] ISO 3685-1993(E). Tool life testing with single point turning tools; 1993.

[26] Standard method for metallographic determination of microstructure in cemented tungsten carbides, B 657, Annual book of ASTM standards. ASTM International. 2003;02.05:386-91.

[27] Singh R, Singh B. Comparison of cryo treatment effect on machining characteristics of titanium in electric discharge machining. International Journal of Automotive and Mechanical Engineering. 2011;3:239-248.

[28] Dhar NR, Kamruzzaman M and Ahmed M. Effect of minimum quantity lubrication on tool wear and surface roughness in turning AISI-4340 steel. Journal of Materials Processing Technology. 2006;172:299-304. 